\title{
Understandings the Reading Habit and Reading Attitudes Among Students in Research University Library in Malaysia
}

\author{
Samsul Farid Samsuddin ${ }^{1} \&$ M. K. Yanti Idaya Aspura ${ }^{2}$ \\ ${ }^{1}$ Department of Library and Information Science, Faculty of Computer Science and Information \\ Technology, University of Malaya, Kuala Lumpur, Malaysia. \\ ${ }^{2}$ Department of Library and Information Science, Faculty of Computer Science and Information \\ Technology, University of Malaya, Kuala Lumpur, Malaysia. \\ Corresponding author email: samsulfarid@um.edu.my \\ DOI: https://doi.org/10.24191/aclim.v1i1.2
}

Received: 31/5/2021 / Accepted: 12/6/2021 / Published Online: 15/7/2021

\begin{abstract}
Reading is one of the activities known to give a lot of benefits to readers. In the context of university students, reading can improve their academic performance. However, literature indicated that students read-only to pass their examination and not for pleasure and acquiring knowledge. The study reported in this paper investigated the reading habit and reading attitudes among students in the research university library in Malaysia. It is believed that positive reading attitudes towards education materials or non-education materials lead to positive reading experiences, which also lead to higher academic performance. A descriptive study used questionnaires as an instrument of a quantitative method. Convenience sampling was employed and 400 respondents from four research university status libraries were selected. Moderate levels of reading attitude were obtained from the result of the study, in which several variables produced a significant relationship in the reading attitude (education background and favorite activities during leisure time). The findings of this study have shown the behavior of academic library users in terms of reading habits, reading attitudes, and selection of reading materials. Several suggestions such as providing a variety of reading material (sense of humor and humanities, public figures and tv personalities) and reading encouragement activities have been suggested. This study provides useful inputs to the Ministry of Higher Education (MOHE) in constructing effective strategies to cultivate reading habits among reluctant readers in public universities.
\end{abstract}

Keywords: reading habits; reading attitude; reading practice; academic library; university library; research university library.

\section{INTRODUCTION}

Reading is one of the abilities of literacy skills, other than writing and counting. Reading skills are the initial skills that a person needs to possess to ensure that they remain competent in daily life. As all know, reading not only can give meaning to a statement, but it can give a deeper understanding to the reader. It also one of the activities known to give a lot of benefits to its readers. Since reading is an activity that has been started since childhood and become a repeated activity for ones in fulfilling their leisure time, obtaining information, and addicting to find some books or reading materials that they like, it is called reading habit (Sari et al., 2020).

Efforts to improve reading activities or inculcate reading habits among the community remain warm although many efforts have been made since time immemorial. The importance of literacy or reading ability among the community is crucial, which acts as a benchmark of a country's development. According to IFLA, the INTERNATIONAL FEDERATION OF LIBRARY ASSOCIATIONS AND INSTITUTIONS, there is a significant relationship between reading research and reading promotion and the role of libraries in lifelong literacy (IFLA, 2019). The National Library 
of Malaysia (NLM) has long been implementing reading programs and campaigns since 1995 through the National Reading Month celebration, with the theme "Mari Membaca Bersama" or "Let's Read Together". Starting 2006, under the leadership of the Ministry of Culture, Arts, and Heritage (KEKKWA), the reading campaign which was previously held throughout July has been made an annual agenda aimed at producing a knowledgeable and informed Malaysian society by making reading a culture. The Reading Campaign Slogan "Bangsa Membaca Bangsa Berjaya" (Successful Nation is a Reading Nation) began to be widely used throughout the country to this day. Besides, Kuala Lumpur has been named the World Book Capital 2020 with the slogan 'KL Baca - Caring Through Reading' by the United Nations Educational, Scientific, and Cultural Organization (UNESCO) (UNESCO, 2019). Accordingly, concerning the recognition, the government has also organized the implementation of the National Reading Decade (DMK) 20212030 through the empowerment of the basic environment of reading encouragement and the mental preparedness of the people aggressively, creatively, and inclusively as a solid foundation.

The Malaysian government has structured all public universities into three categories, namely, research universities, focused universities (the technical education, management, and defense universities), and comprehensive universities. There are presently five universities which are Universiti Malaya (UM), Universiti Putra Malaysia (UPM), Universiti Kebangsaan Malaysia (UKM), Universiti Sains Malaysia (USM), and Universiti Teknologi Malaysia (UTM) given the RU status by the Ministry of Higher Education Malaysia during the 9th and 10th Malaysia Plan out of 20 public Higher Education Institutions (HEIs) (MOHE, 2019). Research universities (RU) in Malaysia are required to focus primarily on research and innovation activities, driven by highly competent academics and competitive student admissions. According to Mohamad Sheriff and Abdullah (2017), RU's are expected to explore their intellectual capacity and become models of Malaysian universities in conducting research activities aimed at knowledge advancement. Seven criteria used by the Assessment of Research Universities Committee to evaluate if a university qualifies to be a research university were namely, 1) quantity and quality of research, 2) quantity and quality of researchers, 3) quantity and quality of postgraduates, 4) Innovation, 5) Professional services and gifts, 6) Networking and linkages, and 7) Support facilities (Mohamad Sheriff and Abdullah, 2017). The RU program was intended to provide a boost that could better inculcate such a research culture in the universities under it.

Due to well-equipped services and facilities in supporting the development of learning, teaching, and research, library users among research university status were chosen as the scope of the study. Besides that, in terms of sufficient budget allocation each year, these academic libraries could maintain the source of reading materials (printed/ electronic) provided to their users. Despite the current deteriorating economic situation happening all over the world. Based on the RU justification, the limitation of times and budget constraints in conducting current research have made RU students in Malaysia respondents to the study. The data obtained from this study although could not be generalized to other public universities possibly it can be used as an example and benchmark to other related studies in the future. Especially on educational institutions that related to reading habits and reading attitudes, and to other institution sources of reference materials available to the local community. Study related to reading profile or reading habits most suitable to be implemented at the level of educational institutions such as schools and institutions of higher learning. It is important to understand and highlight the initiatives taken by a country in supporting reading culture at the education level.

\section{LITERATURE REVIEW}

Nowadays the evolution of the Internet has been impacted the local reading practices that have been practice for ages. The medium and practical of reading have been changing due to Information, Communication, and Technology (ICT) rapidly develops. This phenomenon may change the way people perceive reading and how printed materials are being utilized to facilitate reading. In addition to what has been studied in the past, this study attempts to explore the current reading habits and attitudes among students at a public university in Malaysia. It is also expected to update and provide baseline information about the reading habits and attitudes of Malaysian students.

\section{Related studies}

Studies on reading habits and attitudes among college students globally have gained as much attention in previous years due to the impact of digital media made available through the internet (Liu, 2005; Ramirez, 2003). College students also have been known to be very receptive to different forms of media in their reading and writing practices. This may call for attention among a few researchers to study the evolution of their reading patterns and attitudes, taking into consideration the impact of digital media. Numbers of researchers have carried out their research on the reading habit and attitudes among students in educational institutes in Malaysia. 
Universities or higher institutional students that are connected with the internet or as a user will also be affected by this phenomenon. Abdul Karim and Hasan (2007) who have conducted their study among International Islamic University Malaysia (IIUM) students have reported that students reading attitude is positive and they tend to use electronic and IT resources more than printed. Also, the researchers identified that the students spend about 7 to 9 hours per week on average reading, that related to their academic work. It was also revealed that students spend a significant amount of time reading newspapers, academic books, and websites for leisure and not for educational purposes. In a similar finding, Noor (2011) has conducted a study on reading habits and preferences of English as their foreign language (EFL) postgraduates' students in the Faculty of Social Sciences and Humanities of Universiti Kebangsaan Malaysia (UKM). The researcher has found that the respondents read various types of reading materials, with different reasons for reading as well as language preference in reading. Mostly preferred online reading materials (Internet) and spent about 1 to 2 hours per day on reading.

Ismail and Elias (2009) also have found that the majority of the students have a positive attitude towards reading, but reluctant to English materials and sources that only related to their studies. The study was conducted among English as their second language (ESL) Diploma students at MARA University of Technology Malaysia, Johor. Another study was done by Annamalai and Muniandy (2013) on the reading habit and attitude of the students in a Malaysian Polytechnic have found that the students have low interest in reading and they did not enjoy reading as much as they enjoy doing other technology-related activities. The researchers have adopted Smith's (1991) Adult Survey of Reading Attitude (ASRA) and Pandian's (1997) Reading Habit questionnaire for their study. There were 119 polytechnic students from Engineering and Business departments in the selected Polytechnic who have been involved as respondents. Reflect on this study, it is important to study the current reading habits and attitudes among the population.

Using a similar framework, Ahmed (2016) also revealed that the undergraduate students in her study had an overall positive attitude towards reading. However, the respondents reported faced anxieties and difficulties and had minimal enjoyment of readings. The researcher had a study on reading habits and attitudes of University Malaysia Sabah, Labuan International Campus (UMSKAL) among undergraduates which involved 314 students in 2015 . Another study done on reading habits among Malaysian university students was conducted by Zainol Abidin et al., (2011) which has involved a total of 60 Chinese students studying at the University Tunku Abdul Rahman (UTAR). The outcome of the study reported that a positive general attitude towards reading and most of the respondents spend most of their reading time on schoolwork and completing assignments. It was found that due to several issues and barriers have resulted in the pattern of reading habits and reading attitudes among higher learning institution students.

Although the results of the literature shows were quite historic and not recent, it is a fact that no recent study can be obtained and correlated with the current study being undertaken. Most of the studies that have been conducted involve reading studies that do not consist of students of higher learning institutions and studies related to academic achievement generally. Some studies focus on services and facilities provided by the universities and university libraries only. Nowadays, students are known to be very receptive to different forms of media in their reading and writing practices and things are getting better due to the impacts of the internet. This scenario has geared scholars across the globe to conduct more studies related to the reading habits and attitudes among college students on that status (Abdul Karim and Hasan, 2007; Liu, 2005; Ramirez, 2003).

\section{Statement of gap}

Although university students are believed to have a good record of academic achievement, they do not necessarily have a positive interest in reading, especially in non-academic reading material. Studies done by previous literature have shown a decline in the number of reading information materials, compared to other media of information, and poor reading habits and negative attitude towards reading (Egong, 2014; Owusu-Acheaw, 2014). Most of the studies conducted found that many students read, only to pass their examination and not for pleasure and acquiring knowledge. Support by the finding, Odewole (2019) has concerns on the inability of the students to cultivate reading culture could affect the academic activities and their academic performance, and indirectly affected the quality and standards of a country education program. This would lead to difficulties in attaining meaningful development and growth initiates by the government and the society.

A similar scenario in the Malaysian public university setting, currently there is still lack of studies conducted which then result in less understanding of the current patterns and trends of Malaysian students' reading habits and attitude. In response to this issue, more rigorous studies need to be conducted on the basic level. It also helps the policymakers in providing sufficient and suitable information sources, facilities, and services for academic library users (Samsuddin 
et al., 2020). The purpose of this paper is to investigate the current reading habit and attitudes among students in Research University (RU) library in Malaysia specifically. It is believed that positive reading attitudes lead to positive reading experiences, which also lead to higher academic performance (Abdul Karim and Hasan, 2007).

\section{Goal of study}

This study purpose was to investigate the reading habit and reading attitudes among students in the research university library in Malaysia, and guided by the following research questions:

RQ1: What are the reading habits among the students in the research university library in terms of the following;

1a. Types of reading material they read?

$1 \mathrm{~b}$. Time spend on reading?

1c. Activities during their leisure time?

$1 \mathrm{~d}$. The medium of reading (printed/digitally)?

RQ2: What are the students in research university library attitudes toward reading?

RQ3: What is the relationship between selected demographic factors and their reading attitude?

\section{METHODOLOGY}

This study is a descriptive study in which the sample was selected using convenience sampling. The pre-test has been conducted at selected IPTA's library in Selangor, which involved 5 respondents. The pre-test process is vital as it ensures that students and enumerators can comprehend each of the items and the scale used in the instrument. Meanwhile, the pilot test conducted which involved a total of 30 students from the Universiti Sains Malaysia (USM) has resulted in an acceptable level of internal consistency for each variable (Cronbach alpha above .7) in examining the instrument's reliability. USM was chosen based on its Accelerated Programme for Excellence status (APEX) which is also listed as one of the research universities in Malaysia that have been in the top $1 \%$ of universities worldwide.

\section{Population and sample}

The assessment of the QS World University Rankings, the top 5 rank universities in Malaysia are Universiti Malaya (UM), followed by Universiti Putra Malaysia (UPM), Universiti Kebangsaan Malaysia (UKM), Universiti Teknologi Malaysia (UTM), and Universiti Sains Malaysia (USM) which also have been categorized as Research Universities (RU) in Malaysia. Whereby the student population in research universities in Malaysia according to National Education Statistics for the year 2019 (MOHE, 2019) was 159,621 (N). However, only 4 research universities are involved in this actual data (UM, UPM, UKM, and UTM). Based on Taro Yamane's (2003) sampling procedure, the sample size for students in research universities in Malaysia is 399 respondents. However, the study has collected a total of 400 respondents respectively.

\section{Measurement and data collection}

This study used questionnaires as an instrument of quantitative method which was built based on the research purpose. The study adopted the Adult Survey of Reading Attitude (ASRA) from the work of Smith (1991). The construct was categorized into three variables namely (i) Reading activity and enjoyment (six items); (ii) Anxiety and difficulty (seven items); and (iii) Modality (two items) based on a five-point Likert-type scale ( 5 = "strongly agree"; 1 = "strongly disagree"). While reading habits were analyzed through the types of reading materials read, the amount of time spent on reading per day, their preferences on their leisure time activities, and the type of medium (digitally/ printed) they prefer to read.

Convenience sampling has been implemented due to limited time and budget constraints while conducting the study. Each research university was represented by 100 respondents and conveniently, library users who visit the library within the opening hours during the data collection time were selected and approached as respondents. The research team monitored the data collection process to ensure that the data required can be gathered (100\% response rate).

\section{Data analysis}

Descriptive analysis and Inferential analysis such as frequency, percentage, mean and standard deviation were used to discover the general data of the study. Analysis of variance (ANOVA), independence t-test, and Spearman Rho Correlation were employed to discover the differences and relationships between the reading attitude and the selected demographic factors. Data were examined based on the skewness (.263) and kurtosis (.555) values and considered 
normally distributed when it falls between -2.0 and +2.0 . The decision to use these analyses was based on the distribution of data normality and type of variables. SPSS was used for data analysis purposes (George and Mallery, 2010; Gravetter and Wallnau, 2014).

\section{FINDINGS}

This study has involved a total of 89 male students and 311 female students aged between 18 and 47 years as respondents. Besides, a various background of programs or faculty involved in this current study (Science, Social Science, Medical \& Health, Arts \& Humanities, Computer Science \& IT, Communication, Engineering, Education, Business \& Economics, Agriculture, Language \& Literature, Environment, Account \& Finance, Architecture \& Building, Law \& Legislation, Islamic Studies). In terms of differences, through the independent t-test and ANOVA analysis that has been conducted, there are significant differences in gender $(\mathrm{p}=.031)$, age $(\mathrm{p}=.042)$, and education attainment $(\mathrm{p}=.043)$ with the reading attitude. While, there is no significant difference in student's status, students' program/ field of study, and library distance from their living place. The result showing different results from previous studies conducted by Abdul Karim and Hasan (2007) who have found that there is no significant difference in gender towards reading attitudes. However, in a similar vein, the researcher also found no significant differences between program/field of study with reading attitude.

\section{Type of Reading}

The results of the study found that the main selection of reading type among RU library users is novel (36.5\%) for printed format and academic journal/article (27.3\%) for non-printed format (see Figure 1). This study has proven that the main selection of reading type depends on the type of reading material itself.

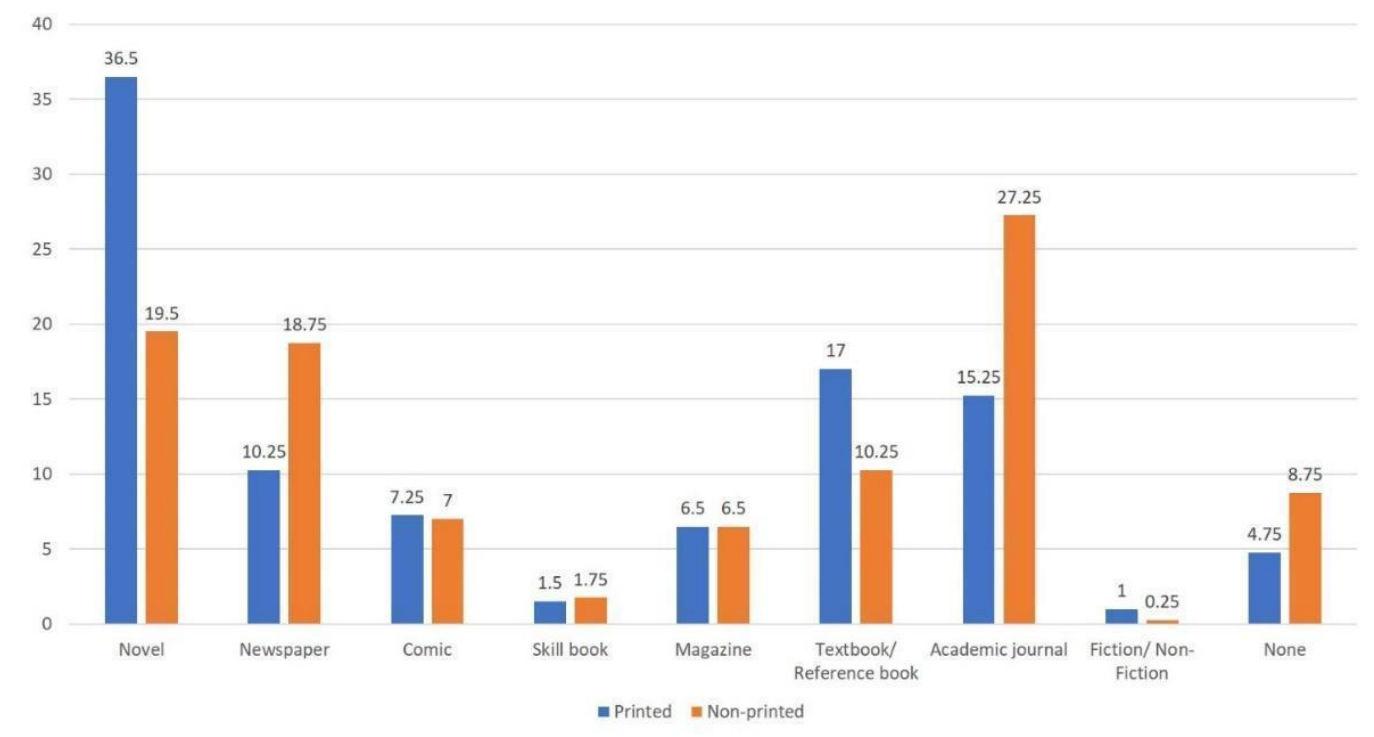

Figure 1: The selection of reading type (Printed and Non-printed)

\section{Time spent reading}

While the findings related to time spend on reading, a majority of respondents in this study (39.5\%) spent about 1 hour to 2 hours a day. There is also a large percentage (35.8\%) spend their reading activities at least less than 1 hour a day (see Figure 2). As a student, it was found that at least in a day they have spent some time reading, regardless of scientific reading material or light reading material. 


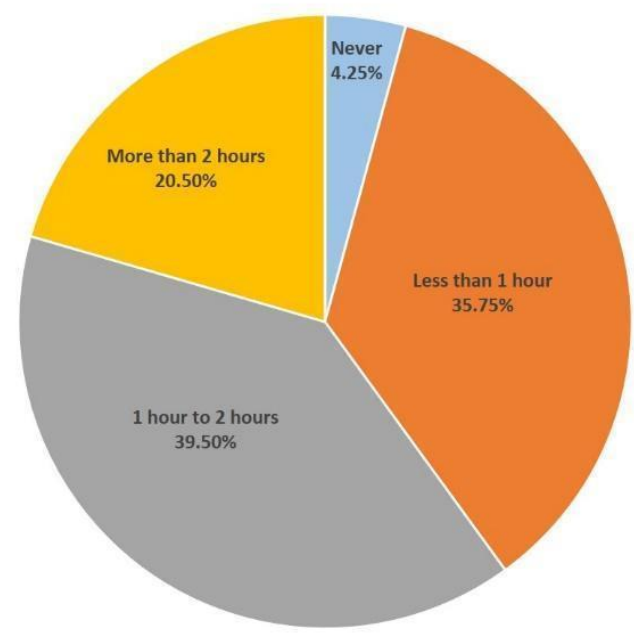

Figure 2: Time spent on reading in a day

\section{Activities during leisure time}

The top activities preferred during leisure time were Internet surfing, which recorded the highest score (39.3\%), followed by watching video/ movie in second place (13.8\%), and in third place shared the equal score at 11.8 percent were reading and listening to music. Based on the data shown in Figure 3, students in higher education institutions are now more inclined towards the use of current technology, namely the Internet. Whether by using a laptop, desktop, or smartphone, ease of access and availability of information and entertainment at your fingertips is a top choice in filling free time. Unconsciously, some have made Internet surfing their daily activity and some have made it a hobby.

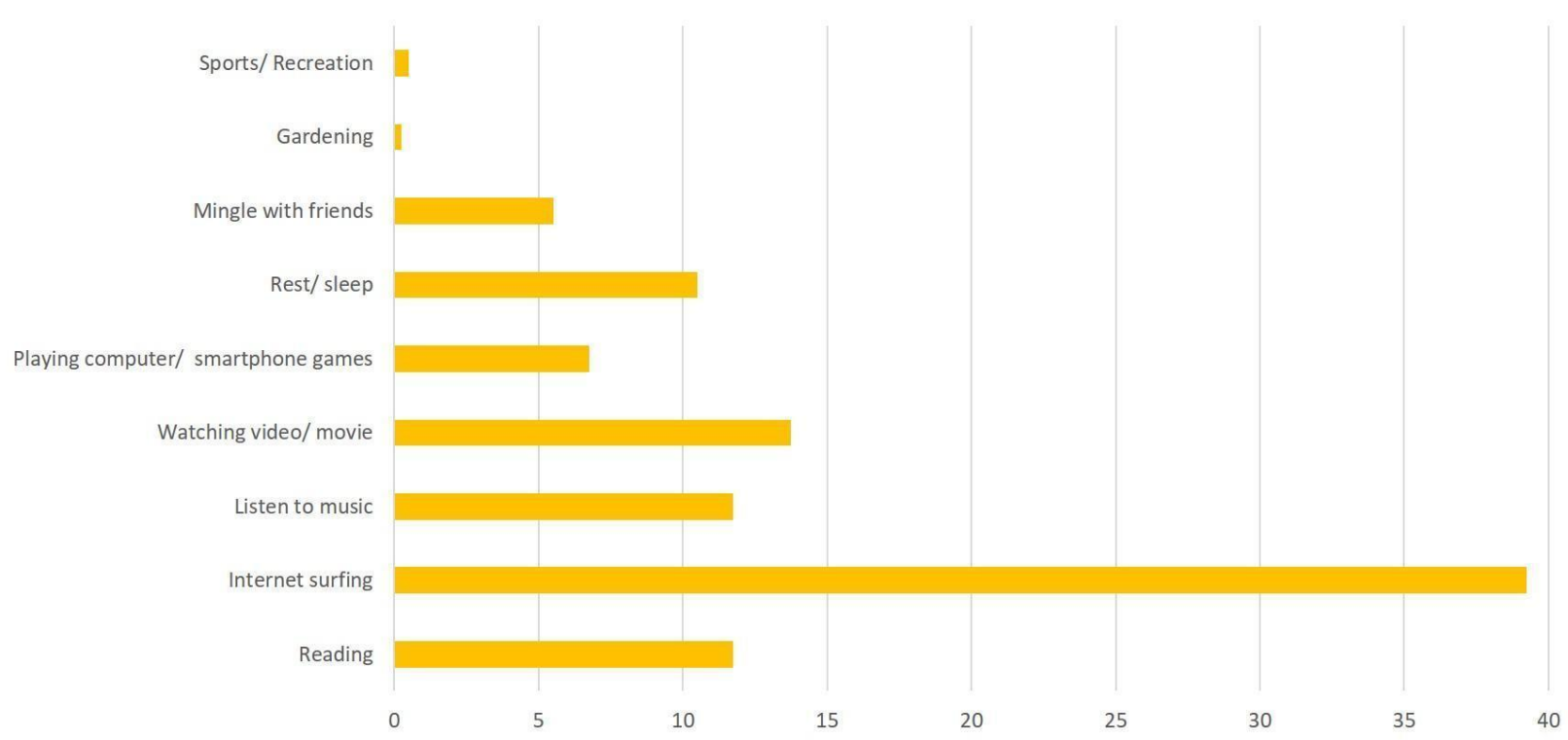

Figure 3: Favorite activities during leisure time 


\section{The Medium of reading format}

In terms of the selection of the most preferred form of reading material, the respondents prefer printed reading material (33\%) compared to non-printed material (32.8\%) and new media (30.3\%) such as social media (see Table 1). However, it is only a slight difference. These findings can further strengthen the initial results obtained in this study which states that the form of reading material whether printed or non-printed it is not the main criterion for the selection of reading material.

Table 1: Medium of reading format

\begin{tabular}{lcc}
\hline Medium & Frequency & Percent \\
\hline Printed & 132 & 33.0 \\
Non-printed & 131 & 32.75 \\
New media/ Social media & 121 & 30.25 \\
None & 16 & 4.0 \\
\hline
\end{tabular}

\section{Reading Attitude}

Answering the second research question, the findings have shown that the attitude towards reading is at a moderate level with the mean score of 3.180 and the majority of the respondents (90\%) showed a positive attitude towards reading (see Table 2). In terms of the distribution of reading attitude variables, each reading activity and enjoyment $(\mathrm{M}=3.598)$ and modality $(\mathrm{M}=3.895)$ was recorded at a high level. While for anxiety and difficulty variable, it is recorded at a moderate level $(\mathrm{M}=2.618)$, which is one of the initial expectations of current researchers. As in Table 3 , the statement "I read when I have time to enjoy it" recorded a high percentage (94\%) among the respondents for the reading activity and enjoyment variable. As for the modality variable, the majority of respondents (96.5\%) agreed with the statement "Reading is one of the best ways for me to learn things". While the statement that recorded the highest percentage (67.5\%) for anxiety and difficulty variable was "Encountering unfamiliar words is the hardest part of reading".

Table 2: Descriptive statistics of reading attitude

\begin{tabular}{lccc}
\hline Variables & N & Mean & S.D. \\
\hline Reading Activity and Enjoyment & 400 & 3.598 & .80130 \\
Anxiety and difficulty & 400 & 2.618 & .87015 \\
Modality & 400 & 3.895 & .77166 \\
Attitude Overall & & 3.180 & .48441 \\
\hline
\end{tabular}

Table 3: Percentage of Reading Attitude statements

\begin{tabular}{lccc}
\hline Statements & $\begin{array}{c}\text { Percentage } \\
\text { agreed (\%) }\end{array}$ & Mean & S.D. \\
\hline Reading activity and enjoyment & & & \\
1. Reading is one of my favorite activities. & 88.5 & 3.675 & .99340 \\
2. I read when I have time to enjoy it. & 94.0 & 3.925 & .86964 \\
3. I get a lot of enjoyment from reading. & 93.5 & 3.833 & .87828 \\
4. I spend a lot of my spare time reading. & 81.0 & 3.328 & 1.00885 \\
5. When I am at home, I read a lot. & 76.0 & 3.213 & 1.09789 \\
6. I want to have more books of my own. & 84.5 & 3.618 & 1.09049 \\
Anxiety and difficulty & & & \\
7. I quickly forget what I have read even if I have just read it. & 66.0 & 2.985 & 1.11485 \\
8. I try very hard, but I just can't read very well. & 38.5 & 2.285 & 1.13225 \\
9. I get upset when I think about having to read. & 38.2 & 2.223 & 1.17108 \\
10. Encountering unfamiliar words is the hardest part of reading. & 67.5 & 2.963 & 1.17667 \\
11. When I read, I usually get tired and sleepy. & 62.7 & 2.885 & 1.13357 \\
12. I often feel anxious when I have a lot of reading to do. & 52.2 & 2.630 & 1.22140 \\
13. I need a lot of help with reading. & 41.2 & 2.353 & 1.23574 \\
\hline
\end{tabular}




\section{Modality}

14. Reading is one of the best ways for me to learn things.

\section{Analysis of relationship on reading attitude}

Factors that are related to reading attitude were education background $(\mathrm{r}=.110 ; \mathrm{p}=.028)$ and favorite activities during leisure time $(\mathrm{r}=-.120 ; \mathrm{p}=.016)$ (see Table 4). Although both factors indicate there is a significant correlation with the attitude of reading, educational background towards positive direction while activities during leisure time towards the negative direction. For other factors such as age, the field of study/ program, library distance from the place of living, student status (part/full-time), time spent on Internet surfing, and time spent on playing games did not record any significant correlations. It can be said that the higher the level of education of a person, the higher the reading attitude possessed by that person. Meanwhile, for the variety of activities that are spent during free time, the more activities that are spent in free time, the lower the reading attitude that a person has. This shows that the higher the level of education of a person, the more demand for increasing the level of knowledge and exploration to the field ventured is necessary.

Table 4: Relationship between selected demographic factors and Reading Attitude among rural library user

\begin{tabular}{lcc}
\hline \multicolumn{1}{c}{ Variables } & $\boldsymbol{r}$ & $\boldsymbol{p}$ \\
\hline Age & .061 & .224 \\
Education Achievement & .110 & $.028^{*}$ \\
Field of Study & .006 & .900 \\
Library Distance & .028 & .570 \\
Student Status & .017 & .738 \\
Time Spent Internet Surfing & .011 & .832 \\
Time Spent Playing Games & .025 & .617 \\
Favorite Activities during Leisure Time &. .120 & $.016^{*}$ \\
\hline
\end{tabular}

*significant at .05 Cronbach alpha

\section{DISCUSSIONS}

\section{Reading Habit and Preferences}

These findings on types of reading material (printed/ non-printed) in line with a previous study done by Ismail and Elias (2009) and Akanda et. al (2013) (see figure 1). Where there is a type of reading material that suitable as the form it is, whether in printed form only or non-printed form only or suitable for both printed and non-printed forms. In this study, it appears the majority of respondents reading novels prefer the printed form. In line with the results of previous studies that found that adolescents are more likely to choose reading materials such as novels as their main reading material (Samsuddin et al., 2020). Besides, the physical form of the novel is smaller than the size of the book such as the main reference books (textbooks), making it more convenient to carry anywhere and be used as primary reading material for those who have a hobby of reading. While the existence of article journals that are mostly available in non-printed form is a top choice for study purposes in choosing the type of non-printed reading material. It also has demonstrated significant similarity with a previous study (Zainol Abidin et al., 2011; Zhang et al., 2017) that indicated that non-printed journal articles are often obtained or used by students in carrying out their learning and research activities at the tertiary level.

Meanwhile, based on the selection of the most preferred form of reading material it was stated that any form of reading material available out there has its fans. Some of them did use these three mediums of reading material when reading. The variety of forms of reading material is very important to be provided to the reader so that it can reach the whole community with a variety of options available. There are arguments from previous researchers on this issue (Ahmed, 2016; Ismail and Elias, 2009; Liu, 2005; Ramirez, 2003). However, if it can be implemented by the publishers and producers regarding the reading material form, the local community will no longer face problems related to access to information and insufficient reading material content. 
Reading culture among students of higher education institutions is indeed positive and very encouraging. This is because of their background and their demands as a student to ensure the sustainability of a future career. It's being debated by previous researchers about the reading culture that is disappearing after they finish their formal learning session (Samsuddin, 2020; Zainol Abidin et al., 2011). Being one of the agenda at present how this culture can be continued with a view, reading as a lifelong learning process. Not just for academic purposes, but more towards selfdevelopment or problem solving, and can also be used as a method of relaxation. As a career person, good time allocation and balance in daily activities are crucial and should be emphasized to achieve a healthier lifestyle in terms of absorbing the ambient pressure.

Based on the activities during leisure times, the result is in line with the findings of previous studies which stated that the Internet and adolescents today cannot be separated (Annamalai and Muniandy, 2013; Mokhtari et al., 2009). Also, the second-highest result which is watching video/ movie has shown that apart from carrying out their main task as a student of higher education institutions, they are no exception in balancing their daily activities with entertainment. Activities such as watching videos/movies and listening to music can indirectly reduce their stress (Samsuddin et al., 2020). The selection of reading as a preferred activity during free time among the other activities by the respondents has meets the expectations of researchers because they are university students who require them to constantly practicing reading activities as a way of learning. The previous study done by Samsuddin et al. (2020) and Akanda et al. (2013) has also stated similar findings in this regard. However, the context of the type of reading that is implemented to fill their leisure time cannot be stated in terms of scientific material or light reading material.

What can be said here, a person's interest in reading regardless of age, chooses the form of their reading material based on the type of reading material itself. The suitability of the form of the reading material whether in printed or nonprinted form reflects the character of the reader who emphasizes terms of the feasibility and availability of the reading material. The existence of the physical form of the reading material can also affect a person's interest in reading the type of material to read. The role of publishers and producers of books in the production of this material at the same time plays a very important role in shaping a person's interest in reading. The choice and decision in the publication of reading materials are noteworthy that it should be compatible with the demands and can supply a variety and adequate reading materials to the reader. However, what is happening in the present, production, and acceptance of companies in producing this book is more focused on the current trend which is only limited to one popular type at a particular time. On the grounds that if publish or produce the kind of books that are not following current trends, the book cannot be sold in the market. Where the criteria of quality and production of various types of books are no longer the main criteria for publishing. This will cause a lack of diversity of reading materials on the market and indirectly narrow the scope of the reader's interest in the selection of reading material that is available only. It is not in line with the reading encouragement campaign that is often held by the relevant parties. This variety of reading material can attract the interest of readers not only in one direction. Apart from the purpose of learning and leisure, reading materials that can form a self-development, sense of humor/ humanities or entertainment such as public figures (tv personalities/ actors) update and local entertainment can increase their general knowledge during reading. Readers, especially teenagers, have more choices in enjoying the reading material they are interested in. This point is very important in the effort to cultivate reading activities among the local community.

\section{Reading attitude among students in Research University library and its relationship on selected demographic factors}

Respondents of this study which consists of students of higher learning institutions have a better level of education due to their educational background. Furthermore, as a student, even if they do not have a high interest in reading, it becomes a necessity for them to master the reading skill. Compared to the level of anxiety and difficulty of rural communities, they scored a higher level because of a lack of formal education in mastering reading skills (Samsuddin et al., 2020). Therefore, activities such as reading skills mastery which are held in rural areas are not suitable for students of higher learning institutions. The campaigns that need to increase can be a reading encouragement that was most appropriate for this category of students. Reading encouragement activities that can be done by academic libraries could be more interactive and youth attract such as active readers awards or reading games attainment. The best planning and innovation in providing this effort is very much demanded to meet the current needs of library users who are increasingly challenging nowadays.

The finding on the relationship of reading attitude with education background was significant with a previous study done by Samsuddin et al. (2020) especially for those who further their study towards higher levels such as Masters and Ph.D., the qualifications of each applicant are different which requires at least a bachelor's degree as a condition 
of admission. The relationship between favorite activities during leisure time and reading attitude, from the findings, Internet surfing, and entertainment-related through movies/ videos watching and listening to music were among the most popular activities. Although these activities seem to conflict with the reading attitude, they can also read for relaxation and entertainment purposes such as by reading comics and entertainment magazines (Wallace, 2003). Among students of institutions of higher learning reading attitude, they have the opposite relationship with their leisure activities. Most of the respondents filled their free time with leisure and more relaxed activities after being tired through the learning process throughout the day. This indirectly shows the positive things that these students know how to divide their time between study and break. The balance they get can relieve their stress while studying in institutions of higher learning.

\section{CONCLUSIONS AND RECOMMENDATIONS}

The overall findings of the study, the purpose of this paper in investigating the reading habit and attitude among students in the research university library in Malaysia is achieved. In terms of reading habits, this paper describes the types of reading material they read; time spend on reading; their favorite activities during leisure time; and the medium of reading they choose. While, high levels of reading attitude were obtained from the result of the study, in which several variables produced a significant relationship in the reading attitude (education achievement and favorite activities during leisure time).

The findings of this study have shown the changes in the behavior of academic library users in terms of usage patterns, attitudes, and selection of reading materials. The existence of digital media may explain the differences in reading behavior among Malaysians. More people are using the web and wireless services to satisfy their information needs and this might negatively affect their reading habits and attitudes towards the printed text materials. This study should be carried out to investigate whether the impacts of ICT affected the reading practices among students in the research university library in Malaysia.

The research data can be referred by researchers/students for future studies especially in the context of digital reading perspectives. This study has provided useful inputs to the Ministry of Higher Education (MOHE) of Malaysia in constructing effective strategies to cultivate reading habits among reluctant readers in public universities. It is also suggested for the policymakers to come out with innovative solutions to continue reading culture after their academic studies through lifelong learning initiatives. Further research could be conducted at the post-educational level, whether to know the reading culture that has been applied can be continued at the career level or not. Sustainability in reading activities is crucial to be continued so that the ability and capability of knowledge development of a country in terms of national literacy rate could be fair in measured through reading activities (seriously or casually).

\section{Acknowledgment}

The team would like to thank the University of Malaya for providing a research grant (GPF003D-2019) for this study.

\section{REFERENCES}

Abdul Karim, N. S., \& Hasan, A. (2007). Reading habits and attitude in the digital age: Analysis of gender and academic program differences in Malaysia. The Electronic Library, Vol. 25 (3), 285-298. DOI: https://doi.org/10.1108/02640470710754805

Ahmed, S. (2016). Reading Habits and Attitudes of UMSKAL Undergraduates. International Journal of Applied Linguistics \& English Literature (IJALEL), Vol. 5 (2), 189-201, DOI: 10.7575/aiac.ijalel.v.5n.2p.189

Akanda, A.K.M. E.A., Hoq, K.M.G. \& Hasan, N. (2013). Reading Habit of Students in Social Sciences and Arts: A Case Study of Rajshahi University. Chinese Librarianship: an International Electronic Journal, 35. Retrieved from http://www.iclc.us/cliej/cl35AHH.pdf

Annamalai, S. \& Muniandy B. (2013). Reading Habit and Attitude among Malaysian Polytechnic Students. International Online Journal of Educational Sciences, Vol. 5 (1), 32-41.

Egong, A. I. (2014). Reading culture and academic achievement among secondary school students. Journal of Education and Practice, 5(3), 132-136. 
George, D. \& Mallery, M. (2010). SPSS for Windows Step by step: A simple guide and Reference, 17.0 update, 10th ed., Pearson: Boston, MA.

Gravetter, F. \& Wallnau, L. (2014). Essentials of Statistics for the Behavioural Sciences, 8th ed., Wadsworth: Belmont, CA.

International Federation of Library Associations and Institutions (IFLA). (2019). About the Literacy and Reading Section. Retrieved from https://www.ifla.org/about-the-literacy-and-reading-section

Ismail, N. \& Elias, S. (2009). An Analysis of the Reading Attitudes and Habits among ESL Part One Diploma Students in MARA, University of Technology Malaysia, Johor Branch. The International Journal of Interdisciplinary Social Sciences, Vol. 4 (8), 181-190.

Liu, Z. (2005). Reading behavior in the digital environment: changes in reading behavior over the past 10 years. Journal of Documentation, Vol. 61 (6), 700-12.

Mohamad Sheriff, N. \& Abdullah, N. (2017). Research Universities In Malaysia: What Beholds ?. Retrieved from http://education.uitm.edu.my/ajue/wp-content/uploads/2018/02/3.MALAYSIA.pdf

Mokhtari, K., Reichard, C.A., \& Gardner, A. (2009). The Impact of Internet and Television Use on the Reading Habits and Practices of College Students. Journal of Adolescent and Literacy, Vol. 52 (7), 609-619.

Noor, N. M. (2011). Reading habits and preference of EFL post graduates: A case study. Conaplin Journal: Indonesian Journal of Applied Linguistics, Vol. 1 (1), 1-8.

Odewole, M. (2019). Reading culture and use of library information resources among the undergraduate students in University of Ilorin. Library Philosophy and Practice (e-journal), 2850. https://digitalcommons.unl.edu/libphilprac/2850

Owusu-Acheaw, M. (2014). Reading Habits Among Students and its Effect on Academic Performance: A Study of Students of Koforidua Polytechnic. Library Philosophy and Practice (e-journal). Paper 1130. http://digitalcommons.unl.edu/libphilprac/1130.

Pandian, A. (1997). Reading in Malaysia, Universiti Kebangsaan Malaysia, Bangi.

QS Quacquarelli Symonds (2020). University Rankings 2021. QS World University Rankings. Retrieved from https://www.topuniversities.com/university-rankings/world-university-rankings/2021

Ramirez, E. (2003). The impact of the internet on the reading practices of a university community: the case of UNAM paper presented at the World Library and Information Congress: 69th IFLA General Conference and Council, Berlin.

Samsuddin, S.F., Mohamed Shaffril, H.A., Bolong, J. \& Mohamed, N.A. (2020). Understanding the reading habit and attitudes among the rural community in low literacy rate areas in Malaysia: Rural library perspectives. Library Management, Vol.41 (1), 39-52, DOI: 10.1108/LM-06-2019-0037

Sari, G.G., Wirman, W. \& Adios, V. (2020). Construction of Reading Meaning for Application User WattpadIndonesia. Jurnal Komunikasi Ikatan Sarjana Komunikasi Indonesia, Vol. 5 (2), 262-268.

Smith, M.C. (1991). An investigation of the construct validity of the adult survey of reading attitude, paper presented at the annual meeting of the College Reading Association, Alexandria, VA. Retrieved from www.cedu.niu.edu/,smith/papers/asra.htm

Ministry of Higher Education of Malaysia (MOHE). (2019). Statistik MOHE. BAB 2 - Universiti Awam. Retrieved from https://www.mohe.gov.my/en/download/awam/statistik/2019-1/613-bab-2-universiti-awam-3/file

Susana, L. \& Mathai, E. J. (2003). Reading Attitudes of UiTM Penang Students: An Exploratory Study. ESTEEM, Vol. 1, 109-120. 
United Nations Educational, Scientific, and Cultural Organization (UNESCO). (2019). Kuala Lumpur named World Book Capital 2020. Retrieved from https://en.unesco.org/world-book-capital-city-2020

Wallace, C. (2003). Reading. Oxford: Oxford University Press.

Yamane, T. (1967). Statistics: An Introductory Analysis, 2nd ed., Harper and Row, New York, NY.

Zainol Abidin, M. J., Pour-Mohammadi, M., \& Ooi, C. L. (2011). The Reading Habits of Malaysian Chinese University Students. Journal of Studies in Education, Vol. 1 (1), 1-13.

Zhang, T., Niu, X., \& Promann, M. (2017). Assessing the User Experience of E-Books in Academic Libraries. College \& Research Libraries, Vol. 78 (5), 578-601, DOI: https://doi.org/10.5860/crl.78.5.578 